Государственное высшее учебное заведение «Криворожский национальный университет», г. Кривой Рог, Украина e-mail: agnu2017@gmail.com

Д. Ю. Малых

Публичное акционерное общество «Ингулецкий горно-обогатительный комбинат», г. Кривой Рог, Украина e-mail: agnu2017@gmail.com

\title{
Технологические способы ведения взрывных работ, позволяющие безопасно управлять действием взрыва в массиве горных пород
}

\author{
S. V. Tychenko /Dr. Sci. (Tech.)/, \\ G. I. Eremenko/Cand. Sci. (Tech.)/ \\ D. Ju. Malykh
}

\author{
State higher educational establishment is the \\ "Kryvy Rih national university", Kryvy Rih, Ukraine \\ e-mail: agnu2017@gmail.com \\ The public joint-stock company of "Ingulets is a \\ mountain concentrating combine", \\ Kryvy Rih, Ukraine \\ e-mail: agnu2017@gmail.com
}

\section{Technological methods for maintenance of explosive works, allowing safely to manage the explosion explosion in the massif of mountain breeds}

Цель. Работа посвящена повышению эфффективности и безопасности уступной взрывной отбойки горных пород скважинными зарядами взрывчатых веществ новой конструкции на железорудных карьерах. Исследованы особенности процесса взрывного разрушения горных пород скважинными зарядами различной конструкции. Установлены зависимости динамики взрывного разрушения от физико-механических свойств горных пород и определена взаимосвязь между распределением энергии разрушения в среде и величиной удельного импульса взрыва.

Методика. Полученные закономерности импульсного воздействия взрыва, связанного с общим балансом энергии, сообщаемой разрушаемой среде, могут служить шкалой оценки эффрективности действия скважинных зарядов, взрываемых одновременно или через определение замедления. На основе полученных теоретических и лабораторных результатов разработана новая конструкция скважинного заряда взрывчатых веществ с воздушной полостью в донной части скважины.

Результаты. Особенностью такой конструкции скважинного заряда является сосредоточение энергии взрыва в донной части скважины. Установлены оптимальные параметры воздушной полости и места расположения инициатора относительно нее в технологии взрывных работ.

Научная новизна работы заключается в том, что проведенные промышленные испытания новой конструкции скважинного заряда с воздушной полостью в донной части скважины показали ее высокую эфроективность.

Практическая значимость состоит в достижении уменьшенного удельного расхода взрывчатых веществ. Этот технологический процесс обеспечивает равномерное дробление взорванной горной массы по всей высоте уступа и качественную проработку подошвы уступа, что открывает реальные возможности для ликвидации перебура скважины при уступной взрывной отбойке горных пород. (Ил. 2. Библиогр.: 11 назв.)

Ключевые слова: горная порода, скважина, процесс взрывного разрушения, отбойка, заряд взрывчатых веществ, конструкция заряда.

В современных условиях добычу руды производят на глубоких горизонтах карьеров. При изменившихся горнотехнических параметрах ведения горных работ, взрывоподготовка горной массы усложняется из-за увеличения удельного веса в разработке крепких, обводненных горных пород.

Другой причиной, усложняющей проблему обеспечения горного производства качественно 
взорванной горной массой, является нарушение естественной структуры горного массива предыдущими взрывами. В сложившихся условиях область массива, примыкающая к свободным поверхностям разрушаемого уступа горных пород, часто является зоной нерегулируемого дробления. Кроме того, постоянный рост себестоимости работ по буровзрывному комплексу, широкое внедрение новых взрывчатых материалов требует новых решений в технологии ведения взрывных работ.

Взрывоподготовка горной массы оказывает прямое влияние на технико-экономические показатели добычи полезного ископаемого открытым способом.

Методы управления энергией взрыва при отбойке горных пород в основном разрабатывались для условий многорядного короткозамедленного взрывания. Переход взрывных работ на узкие рабочие площадки большой длины приводит к невозможности использовать многорядное традиционное производство взрывных работ. Параллельно в современных условиях экономическая целесообразность диктует использование эмульсионных ВВ, переход на средства низкоэнергетического неэлектического инициирования. Данные факторы указывают на необходимость разработки новых методов ведения взрывных работ, отвечающих концепции повышения их эффективности и безопасности в условиях глубоких железорудных карьеров.

Разработанный способ эффективного и безопасного управления действием взрыва заключается в следующем (рис. 1a, б).

При разработке рудного тела бурят скважины 2 и формируют в них заряды ВВ 3. Скважины на уступе 1 бурят в соответствии с разработанным паспортом буровзрывных работ, исходя из технологии ведения горных работ и физико-механических свойств горных пород.

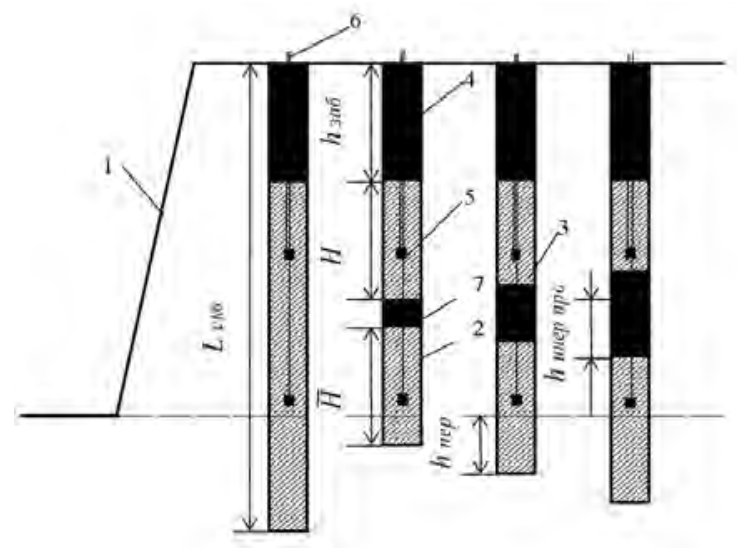

a)
Составляющие технологии ведения взрывных работ в значительной степени предопределяют характер распределения энергии взрыва в разрушаемом массиве горных пород, что, в свою очередь, влияет на общую безопасность и эффективность ведения взрывных работ. Технология ведения взрывных работ включает в себя способы размещения, формирования и инициирования скважинных зарядов ВВ.

При решении многих теоретических задач по взрыву используют гидродинамическую модель рассматриваемых процессов. Схемы построения математических моделей взрывного разрушения твердой среды основаны на качественном анализе рассматриваемого явления. Причем при необходимости сложные процессы расчленяются на отдельные предельно простые блоки, учитывающие только самые основные черты явления. После строгой формулировки отдельные блоки сводятся в одно решение поставленной задачи в целом, не вызывающей затруднений с чисто математической стороны.

Развитие гидродинамическая теория разрушения получила в работах [1-5]. Рассмотрим вопрос о расширении цилиндрической взрывной полости в условиях идеальной несжимаемой жиДкости.

В условиях цилиндрической симметрии поле скоростей имеет вид, м/с:

$$
v=f(t) / r,
$$

где $r$ - расстояние от оси заряда, м;

$f(t)$ - функция времени.

Для газового пузыря при радиальном расширении, Дж:

$$
E_{\kappa}=\rho \int_{a}^{\infty} v^{2} \pi r d r,
$$

где $a$ - радиус расширяющейся взрывом камеры, $\rho$ - плотность среды.

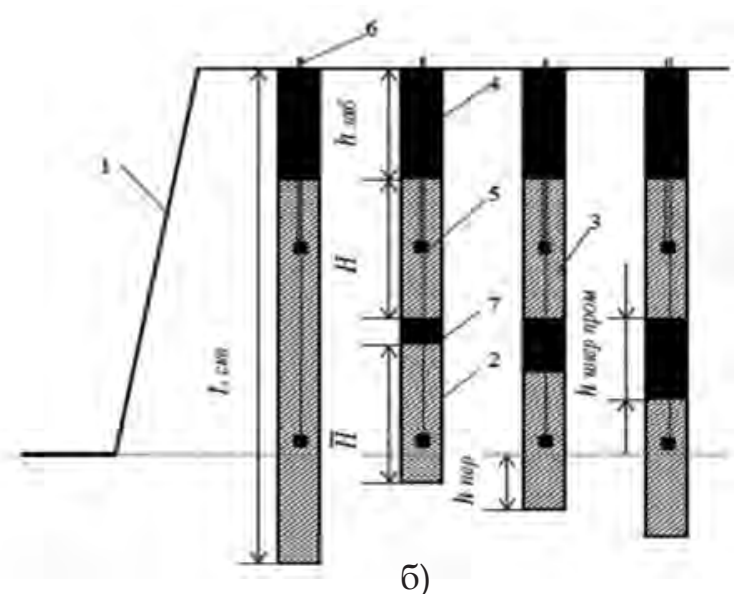

б)

Рис. 1. Способ безопасного управления действием взрыва скважинных зарядов с линейно дифференцированным взрывчатым веществом (ВВ): 1 - уступ; 2 - скважины; 3 - ВВ; 4 - забойка; 5 - промежуточный детонатор; 6 - волноводы; 7 - инертный промежуток 
Теоретические решения для случая сферической симметрии дают хорошие результаты в сравнении с экспериментальными. Невозможность распространения результатов сферической симметрии на случай цилиндрической, заставила исследователей изменить подход к данному вопросу. Для задачи о цилиндрической газовой полости [6] были использованы результаты исследований [7]. В идеальном случае было получено уравнение:

$$
a \cdot a^{\prime \prime}+\frac{3}{4} a^{\prime 2} \cong(P(a)-P(\infty))(2 \rho)^{-1},
$$

где $P(a)$ - давление газа в полости (Па);

$P(\infty)$ - давление на бесконечности (Па).

В работе [8] при рассмотрении данной задачи было учтено, что в реальных условиях присутствует свободная поверхность, и отношение максимального радиуса газовой камеры скважинного заряда к его высоте $h$ во много меныше единицы. Из предположения, что во времени движения газовый пузырь имеет форму кругового цилиндра, а свободная поверхность горизонтальна, было получено дифференциальное уравнение:

$$
\frac{1}{2} a^{2} \cdot a^{\prime 2} \cdot \ln (2 h / a)=I \rho^{-1},
$$

описывающее расширение газового пузыря цилиндрического заряда ВВ, Нс:

$$
I=\int_{a_{0}}^{a}(P(a)-P(\infty)) a d a .
$$

Время расширения полости согласно исследованиям, выполненным в работе [8], может быть определено как:

$$
T=(A / B C)^{1 / 2} \int_{a_{\mathrm{o}}}^{a_{\kappa}}\left(\left(a_{\kappa} / a\right)^{2 A}-1\right)^{-1 / 2} d a,
$$

где коэффициенты $A, D, C$ определяются согласно формул:

$$
\begin{gathered}
A=1+\alpha(1-\varepsilon) /\left(1-\varepsilon^{1 / 2}\right)+\alpha\left(\varepsilon-\varepsilon^{\alpha / 2}\right) /\left(2-\varepsilon^{\alpha / 2}\right), \\
B=\alpha / \rho\left(\varepsilon^{-\alpha / 2}-1\right), \\
C=K\left(\varepsilon^{\alpha / 2}-1\right) / 2 m-P \cdot \varepsilon^{\alpha / 2},
\end{gathered}
$$

где $\varepsilon$ - объемная деформация(\%);

$\alpha=2 m /(1+m) ; m \approx \sqrt{3}(0,1-0,4)$.

На основе гидродинамической модели действия взрыва рассмотрим вопрос определения границ зоны разрушения и гранулометрического состава взорванной горной массы при взрыве одиночного заряда ВВ в неорганической среде.

Для решения этой задачи в работе [9] кинетическая энергия жидкости в объеме куба с ребром $2 l$ была приравнена к энергии упругой деформации.

Процесс рассматривался в прямоугольной декартовой системе координат, т.е.:

$$
E_{\kappa}=E_{0} \text { и } d=\sqrt{3} \cdot v_{s} / \sqrt{D} \cdot v_{s}=\sigma_{s} / \sqrt{E \rho},
$$

где $v_{s}$ - критическая скорость, м/с;

$\sigma_{s}-$ прочность при сжатии и растяжении, н/ $\mathrm{M}^{2}$.

Формула, отражающая плотность упругой энергии для несжимаемой среды, имеет вид, Дж/кг·К:

$$
\omega=T^{2} / 2 \mu,
$$

где $\mu=E / 2(1+v)$ - модуль сдвига;

$T$ - интенсивность касательных напряжений.

Если обозначить через $T_{s}$ значение $T$, соответствующее разрушению, то выражение, согласно [5], для критической скорости и величины осколка примет вид:

$$
v_{3}=T_{3} / \sqrt{\mu \rho}, l=T_{s} \sqrt{6} / H \sqrt{\mu \beta},
$$

где $H$ - скорость деформации сдвига.

Для случая сдвига имеем:

$$
v_{s}=\tau_{s} / \sqrt{\mu \beta}, l=\tau_{s} \sqrt{3} / \sqrt{\mu \rho D},
$$

где $D$ - критерий дробимости, $\tau_{s}$ - предел текучести на сдвиг.

Для определения размера зоны разрушения цилиндрического заряда примем за потенциал скорости и критерий дробимости значение в виде:

$$
\begin{aligned}
\varphi & =-m / r, D=6 m^{2} \\
r & =\sqrt{x^{2}+y^{2}+z^{2}}, \\
m & =\left(\alpha E_{0} r_{0} / 2 \pi \rho\right)^{1 / 2}
\end{aligned}
$$

где $x, y, z$ - текущие декартовы координаты.

Определим размер $R_{s}$ зоны разрушения, при котором размер куска равен расстоянию от центра взрыва.

Если $R_{s}>>r_{\mathrm{o}^{\prime}}$ то, М:

$$
R_{s}=\left(\alpha E_{0} r_{0} / \rho v_{s}^{2}\right)^{\frac{1}{4}} .
$$

Учитываем особенности формирования скважинных зарядов с линейно дифференцированным BВ:

$$
H \geq \bar{H},
$$

где $H$ - длина верхнего заряда ВВ (м);

$\bar{H}$ - длина нижнего заряда ВВ (м).

Длина каждого последующего инертного промежутка и перебура:

$$
\begin{gathered}
h_{i}=\bar{h}_{i}=h_{0}+m(i-2), \quad(i=2,3, \ldots), \\
m=0,025 f
\end{gathered}
$$

где $h_{0}$ - минимально допустимая длина инертного промежутка по паспорту БВР, м;

$h_{i}$ - длина инертного промежутка $i$-й скважины (M);

$\bar{h}_{i}$ - длина перебура $i$-й скважины, м;

$m$ - коэффициент линейной дифференциации зарядов ВB; 
$f$ - коэффициент крепости горных пород по шкале проф. М. М. Протодьяконова.

Последняя формула примет вид, м:

$$
R s^{4}=\left(\operatorname{aro}\left(T_{1}+T_{2}\right) 1+\sum_{i-1}^{n}\left(T_{1}+T_{2}\right) i+1 / G\right),
$$

где $G=\pi \rho v_{s}^{2}$

Тогда размер среднего куска в нашем случае определяется как, м (рис. 2):

$$
d_{c p}^{4}-0,5\left[\left(\operatorname{aro}\left(T_{1}+T_{2}\right) 1\right)+\sum \downarrow\right.
$$

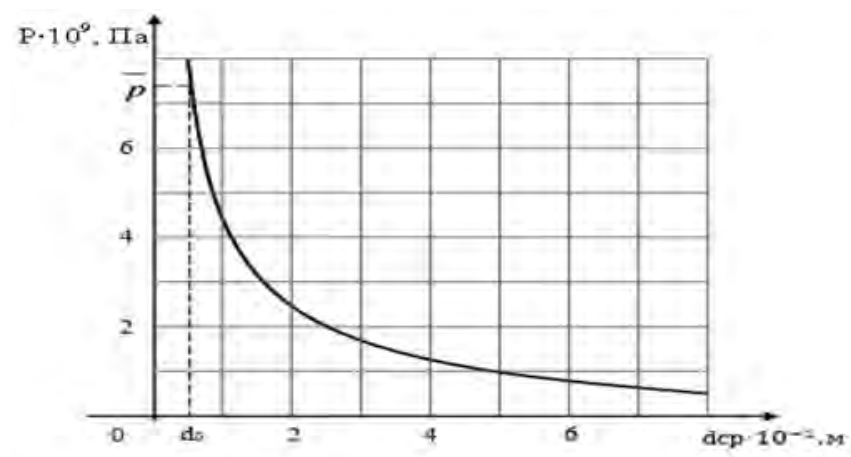

Рис. 2. Зависимость процесса разрушения $d_{c p}$ от величины нагрузки $P$

Формулы (1) и (2) отражают закономерности распределения гранулометрического состава взорванной горной массы и зоны разрушения от энергетических характеристик взрывной нагрузки, учитывая особенности формирования скважинных зарядов с линейно дифференцированным ВВ.

Используя при расчетах скважинных зарядов коэффициент $m$ линейной дифференциации, можно формировать сважинные заряды так, чтобы снизить одновременно отрицательное взрывное воздействие как на нижележащий, так и на смежный уступ. Это достигается за счет перераспределения ВВ в разрушаемом уступе горных пород, тем самым уменьшаются зоны хаотической искусственной системы структурных нарушений и заколов от действия произведенного взрыва.

Использование коэффициента линейной дифференциации зарядов ВВ $(m)$ позволяет очень легко производить расчет параметров скважинных зарядов [10; 11] при применении разработанного способа разрушения горных пород.

\section{Выводы}

Разработанный технологический процесс проведения взрывных работ на карьерах при меньшем удельном расходе взрывчатых веществ обеспечивает равномерное дробление взорванной горной массы по всей высоте уступа и качественную проработку его подошвы, что открывает реальные возможности для ликвидации перебура скважин при уступной взрывной отбойке горных пород.

\section{Библиографический список / References}

1. Механический эффект подземного взрыва / В. Н. Родионов, В. В. Адушкин и др.; под. ред. А. Садовского. - М.: Недра, 1971. - 220 с.

Rodionov. V. N., Adushkin V. V. Mekhanicheskiy effekt podzemnogo vzryva. Mosocw, Nedra, 1971, 220 p.

2. Комплексное исследование действия взрыва в горных породах / Э. О. Миндели, Н. Ф. Кусов,
$\left.l=1)^{m}=\left(T_{1}+T_{2}\right) i+1\right] \uparrow(-1) \cdot G^{-2}$

А. А. Корнеев, Г. И. Марцинкевич. - М.: Недра, 1978. - 253 c.

Mindeli E. O., Kusov N. F., Korneev A. A., Martsinkevich G. I. Kompleksnoe issledovanie deystviya vzryva $v$ gornykh porodakh. Mosocw, Nedra, 1978, 253 p.

3. Вибухові роботи / В. Ф. Бизов, П. І. Федоренко. - Кривий Ріг: Мінерал, 2001. - 230 с.

Bizov V. F., Fedorenko P. I. Vibukhovi roboti. Kriviy Rig, Mineral, 2001, 230 p.

4. Баранов Е. Г. Оценка энергоемкости горных пород при взрыве / Е. Г. Баранов, В. Е. Клаповский / / ФТПРПИ. - 1969. - № 5. - С. 85-94.

Baranov E. G., Klapovskiy V. E. Otsenka energoemkosti gornykh porod pri vzryve. FTPRPI, 1969, no. 5, pp. 85-94.

5. Баренблатт Г. И. Математическая теория равновесных трещин, образующихся при хрупком разрушении / Г. И. Баренблатт / / ПМТФ. 1969. - № 4. - С. 3-56.

Barenblatt G. I. Matematicheskaya teoriya ravnovesnykh treshchin, obrazuyushchikhsya pri khrupkom razrushenii. PMTF, 1969, no. 4, pp. 3-56.

6. Дремин А. Н. Детонационные волны в конденсированных средах / А. Н. Дремин, С. Д. Савров, В. С. Трофимов, К. К. Шведов. - М.: Наука, 1971. - 162 c.

Dremin A. N., Savrov S. D., Trofimov V. S., Shvedov K. K. Detonatsionnye volny v kondensirovannykh sredakh. Mosocw, Nauka, 1971, 162 p.

7. Кузнецов В. М. О плоской волне разрушения / В.М. . Кузнецов // ФГВ. - 1974. - № 1. C. $124-127$.

Kuznetsov V. M. O ploskoy volne razrusheniya. FGV, 1974, no. 1, pp. 124-127.

8. Кузнецов В. М. Математические модели взрывного дела / В. М. Кузнецов. - Новосибирск: Наука, 1977. - 259 с.

Kuznetsov V. M. Matematicheskie modeli vzryonogo dela. Novosibirsk, Nauka, 1977, 259 p.

9. Родионов В. Н. К вопросу о повышении эффективности взрыва в твердой среде / В. Н. Родионов. - М.: Изд-во ИГД АН СССР, 1962. - 29 с.

Rodionov V. N. K voprosu o povyshenii effektivnosti vzryva $v$ tverdoy srede. Moscow, Izd-vo IGD AN SSSR, 1962,29 p. 
10. Тищенко С. В. Эффективность использования энергии взрыва при взрывании скважинного заряда взрывчатыми веществами / С. В. Тищенко, Г. И. Еременко, Д. Ю. Малых / / Науковотехнічний збірник. - 2014. - Вип. 97.

Tishchenko S. V., Eremenko G. I., Malykh D. Yu. Effektionost' ispol'zovaniya energii vzryva pri vzryvanii skvazhinnogo zaryada vzryvchatymi veshchestvami. Naukovo-tekhnichniy zbirnik, 2014, issue 97.

11. Тищенко С. В. Разработка способов взрывной отбойки горных пород в железорудных карьерах / С. В. Тищенко, Г. И. Еременко, Д. Ю. Малых // Відомості Академії гірничих наук України. - 2017. Вип. 8.

Tishchenko S. V., Eremenko G. I., Malykh D. Yu. Razrabotka sposobov vzryvnoy otboyki gornykh porod $v$ zhelezorudnykh kar'erakh. Naukovo tekhnichniy zhurnal Vidomosti Akademiï girnichikh nauk Ukrainy, 2017, issue 8.

Meта. Робота присвячена підвищенню ефрективності та безпеки уступної вибухової відбійки гірських порід свердловинними зарядами вибухових речовин нової конструкції на залізорудних кар'єрах. Досліджено особливості процесу вибухового руйнування гірських порід свердловинними зарядами різної конструкції. Встановлено залежності їх динаміки вибухового руйнування від фрізико-механічних властивостей гірських порід і визначено взаємозв'язок між розподілом енергії руйнування в середовищі і величиною питомого імпульсу вибуху.

Методика. Отримані закономірності імпульсного впливу вибуху, пов'язаного із загальним балансом енергії, що повідомляється середовищу, яке руйнується, можуть служити шкалою оцінки ефрективності дії свердловинних зарядів, що підриваються одночасно або через визначення уповільнення. На основі отриманих теоретичних і лабораторних результатів розроблено нову конструкцію свердловинного заряду вибухових речовин з повітряною порожниною в донній частині свердловини.

Результати. Особливістю такої конструкції свердловинного заряду є зосередження енергії вибуху в донній частині свердловини. Встановлено оптимальні параметри повітряної порожнини і місия розташування ініціатора щодо неї в технології вибухових робіт.

Наукова новизна роботи полягає в тому, що проведені промислові випробування нової конструкції свердловинного заряду з повітряною порожниною в донній частині свердловини показали ї високу ефрективність.

Практична значущість полягає в досягненні зменшеної питомої витрати вибухових речовин. Цей технологічний прочес забезпечує рівномірне дроблення підірваної гірничої маси по всій висоті уступу і якісне опрацювання підошви уступу, що відкриває реальні можливості для ліквідації перебуру свердловини при уступній вибуховій відбійці гірських порід.

Ключові слова: гірська порода, свердловина, процес вибухового руйнування, відбійка, заряд вибухових речовин, конструкція заряду.

Purpose. The work is devoted to improving the efficiency and safety of the escarpous blasting of rocks by borehole charges of explosives of a new design at iron ore quarries. In the thesis, the features of the process of explosive destruction of rocks by well charges of various designs are investigated. The dependences of their dynamics of explosive destruction on the physicomechanical properties of rocks are established, and the relationship between the distribution of energy of destruction in the medium and the magnitude of the specific impulse of the explosion is determined.

Metodology. The obtained regularities of the impulse effect of an explosion associated with the overall energy balance imparted to a destructible medium can serve as a scale for evaluating the effectiveness of the action of well charges exploded simultaneously or through the definition of deceleration. Based on the obtained theoretical and laboratory results, a new design of a downhole charge of explosives with an air cavity in the bottom of the well has been developed.

Findings. A feature of this design of the borehole charge is the concentration of the explosion energy in the bottom of the well. The optimal parameters of the air cavity and the location of the initiator relative to it in the technology of blasting have been established.

Originality of the work lies in the fact that the conducted industrial tests of a new design of a borehole charge with an air cavity in the bottom part of the well showed its high efficiency.

Practical value lies in achieving a reduced specific consumption of explosives. This technological process ensures uniform crushing of the blasted rock mass over the entire height of the ledge and high-quality development of the bottom of the ledge, which opens up real opportunities for the elimination of the re-drilling of the well at the inferior explosive blasting of rocks.

Key words: rock, well, process of explosive destruction, blasting, charge of explosives, charge design.

Рекомендована к публикации д. т. н. С. А. Жуковым

Поступила 13.09.2018

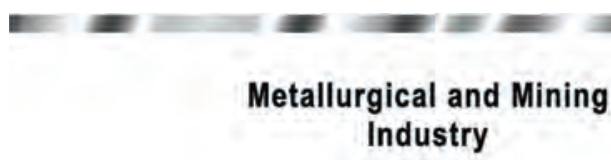

